\title{
Newest Update in Heart Failure Guidelines Recommendation
}

Hasanah Mumpuni

Department of Cardiology and Vascular Medicine, Faculty of Medicine, Public Health and Nursing, Universitas Gadjah Mada Dr. Sardjito General Hospital, Yogyakarta, Indonesia

Corresponding author:

Hasanah Mumpuni, MD, - email: hmumpuni@ugm.ac.id

Department of Cardiology and Vascular Medicine, Faculty of Medicine, Public Health and Nursing, Universitas Gadjah Mada - Dr.Sardjito Hospital

Jalan Farmako Sekip Utara, Yogyakarta, Indonesia 55281

\section{ABSTRACT}

Heart failure remains a global burden despite important progress that has been made in the management of heart failure. Guidelines from ESC and AHA are still widely used as a guidance for diagnosis and management of heart failure. We will discuss the new recommendation from ESC and AHA guideline for heart failure.

\section{Introduction}

On the 2012 guideline, heart failure was classified into 2 categories based on fraction ejection, heart failure with reduced ejection fraction (HFrEF) for ejection fractions below $40 \%$ and heart failure with preserved ejection fraction (HFpEF) for ejection fractions above $50 \%$. This classification can also illustrate the pathophysiological differences between HFrEF and HFpEF wherein HFrEF involves volume overload while the pathophysiology of HFpEF involves pressure overload. However, the 2012 guidelines still leave the gray area for ejection of $40-49 \%$ fraction. So that in the latest guideline, the ejection fraction of 40 $49 \%$ is grouped into a new classification, namely heart failure with mid-range ejection fraction (HFmrEF). This classification is expected to encourage more research in this population because until now only in the HFrEF group has it been proven that administration of heart failure therapy can reduce mortality and morbidity. ${ }^{1}$

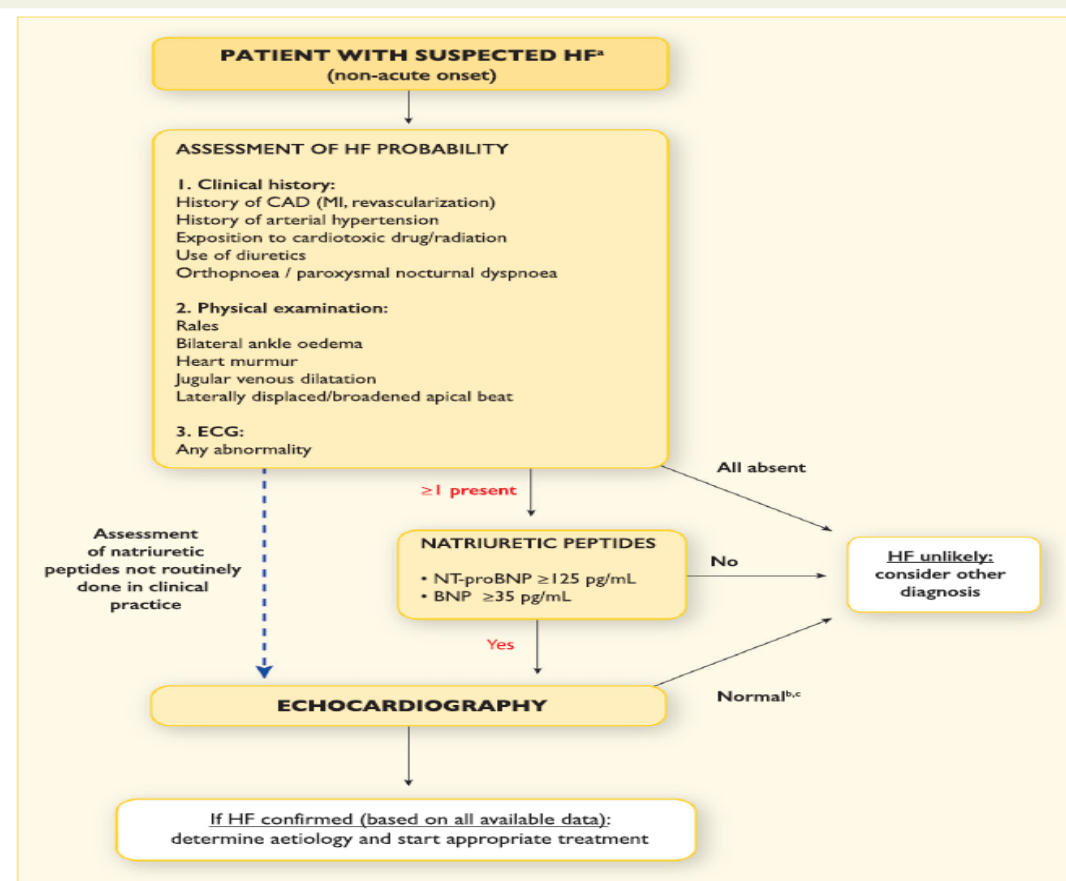

Figure 1. Algorithm for diagnosing heart failure in non-acute conditions ${ }^{1}$ 
The latest guidelines also add an algorithm to enforce the diagnosis of heart failure in a non-acute setting (Figure 1). The algorithm starts with assessing the probability of a diagnosis of heart failure by looking at the patient's clinical history, physical examination and ECG. If there is no abnormality in one of the clinical points, it is unlikely that the patient will have heart failure so another diagnosis is needed. However, even if only 1 abnormality is found, an NT pro BNP examination is necessary. An echocardiographic examination is performed if there is an increase in levels of NT pro BNP. ${ }^{1}$

The most important point added to the latest guideline is management of heart failure, especially HFrEF. At the latest guildeline of ESC and AHA, new therapies for reduced EF heart failure management algorithms are added, namely ARNI therapy (angiotensin-renin and neprylisin inhibitors) and ivabradine. ARNI therapy that has been tested is a combination of sacubitrile-valsartan, and is known to work by inhibiting neprilysin, which is the degradation of natriuretic peptides. Sacubitril-valsartan is recommended as an ACE inhibitor replacement therapy in symptomatic HFrEF patients even with optimal treatment of ACE inhibitors, beta blockers and mineral corticoid-receptor antagonists, and from several studies proven to reduce the risk of hospitalization and death. However, ARNI should not be given in conjunction with an ACE inhibitor and is recommended starting 36 hours after the last dose of ACE inhibitor. ARNI therapy is also not recommended for patients with a history of angioedema. ${ }^{1,2}$

From the latest clinical trial, ivabradine therapy is known to reduce hospitalization in heart failure patients with reduced EF who are still symptomatic with optimal therapy (ACE inhibitors, beta blockers). So that in the latest guideline, it is recommended to be given to heart failure patients with reduced EF, who are still symptomatic even with optimal therapy, with a sinus rhythm ECG and a pulse of $\geq 70$ times per minute. ${ }^{1,3,4}$

Table 1. Recent recommendations for HFrEF management according to ESC

\section{Guidelines $^{1}$}

\begin{tabular}{|l|c|c|}
\hline Recommendation & Class & $\begin{array}{c}\text { Level of } \\
\text { evidence }\end{array}$ \\
\hline $\begin{array}{l}\text { Sacubitril / valsartan is recommended as an ACE inhibitor } \\
\text { replacement therapy in HFrEF patients who still have } \\
\text { symptoms even with optimal ACE inhibitor, beta blockers } \\
\text { and mineralcorticoid antagonist therapy }\end{array}$ & I & \\
\hline $\begin{array}{l}\text { Ivabradine can be considered for administration to } \\
\text { patients with HFrEF, has a sinus rhythm with a resting } \\
\text { pulse } \geq 70 \text { times per minute, who still has symptoms even } \\
\text { with optimal beta blocker, ACE inhibitors, and } \\
\text { mineralcorticoid antagonist therapy }\end{array}$ & B \\
\hline $\begin{array}{l}\text { Ivabradine can be considered for administration to } \\
\text { patients with HFrEF, has a sinus rhythm with a resting } \\
\text { pulse } \geq 70 \text { times per minute, who has ACE inhibitor and } \\
\text { mineralcorticoid antagonist therapy but has } \\
\text { contraindications for administration of beta blockers or } \\
\text { cannot tolerate administration of beta blockers. }\end{array}$ & & \\
\hline
\end{tabular}


Table 2. Recent recommendations for HFrEF management according to the AHA Guideline ${ }^{2}$

\begin{tabular}{|l|c|}
\hline \multicolumn{1}{|c|}{ Recommendation } & Class \\
\hline HFrEF patients who can tolerate ACE inhibitors or ARBs but are still \\
symptomatic with NYHA II-III, replacement of ACE inhibitors or ARBs with \\
ARNI is recommended to reduce morbidity and mortality
\end{tabular}

\section{References}

1. Ponikowski P., Voors A., Anker S., Bueno H., Cleland J., Coats A., et al. 2016. 2016 ESC Guidelines for the diagnosis and treatment of acute and chronic heart failure. Eur Heart $J, 37: 2129-2200$.

2. Yancy C., Jessup M., Bozkurt B., Butler J., Casey D., Colvin M., et al. 2017. 2017 ACC/AHA/HFSA
Focused update of the 2013 ACCF/AHA guideline for the management of heart failure: $A$ Report of the American College of Cardiology/American Heart Association Task Force on Clinical Practice Guidelines and the Heart Failure Society of America. Circulation, 8;136:e137e161. 